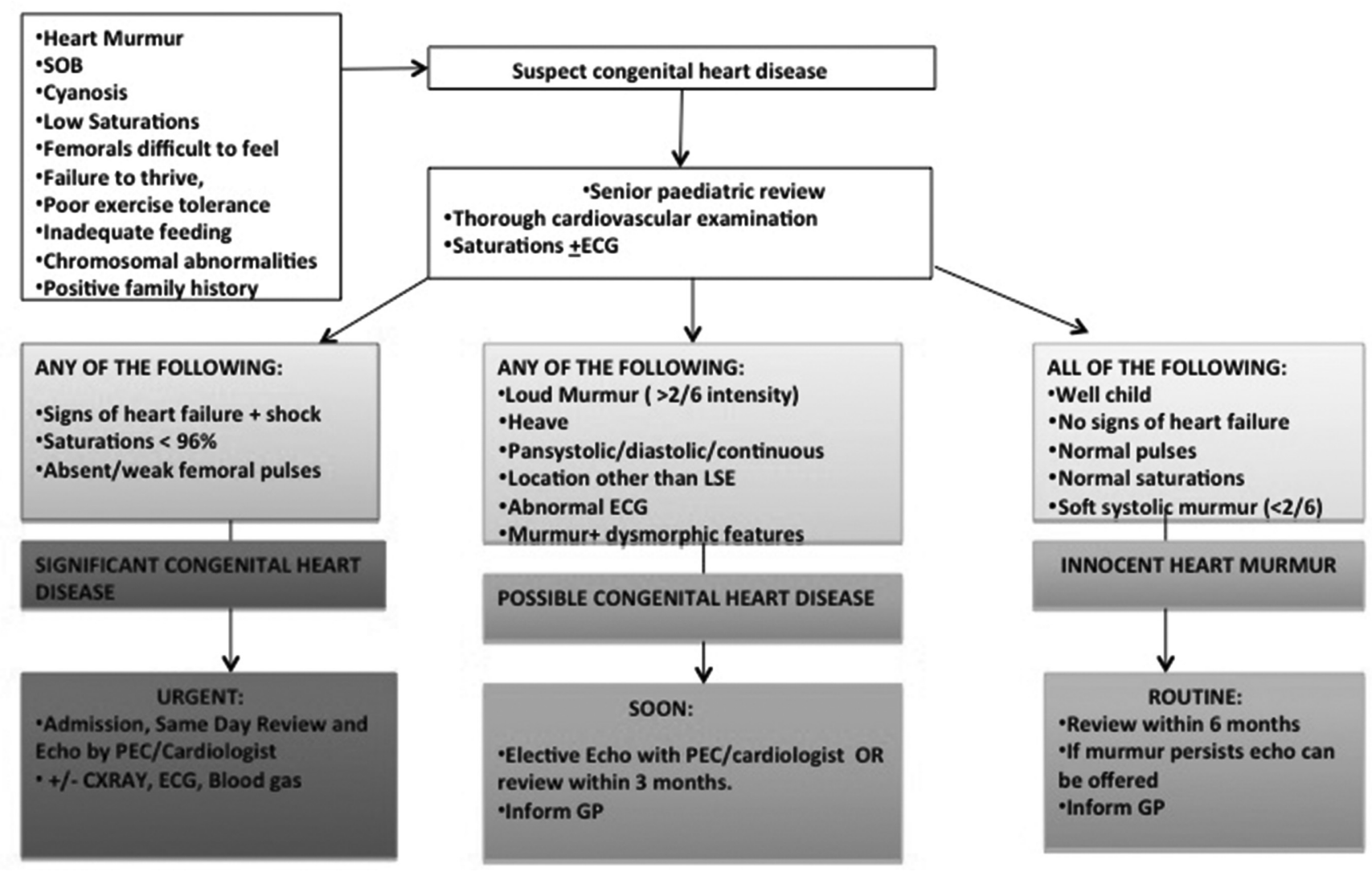

Abstract G92(P) Figure 2 Older children murmur algorithm

Results Medline returned 1204 results, Embase (1168), Cochrane (0), Cinahl (131), Psycinfo (15), Amed (13), British nursing index (5), DARE (0) and CENTRAL (8). When duplicates were removed 2533 results remained from which 560 articles were selected according to suitability. Among these 100 original papers were fully accessed and reviewed. Based on the available evidence a guideline triaging patients into a traffic-light system according to clinical severity with an algorithm for investigation was developed, taking into account patient feedback and opinions from experts in the field (Figures 1 and 2).

Conclusion A new, easy to follow guideline has been implemented, which will aid clinicians to confidently triage children presenting with murmurs according to clinical need and guide appropriate management. This will promote quality of care and patient safety, and facilitate the management of children with murmurs who attend the CED.

\section{G93(P) DO AS I SAY, NOT AS I DO? DIFFERENCES BETWEEN PERCEIVED AND ACTUAL PRACTICE IN THE FOLLOW UP OF MICROSCOPIC HAEMATURIA/PROTEINURIA IN FEBRILE CHILDREN SEEN IN THE CHILDREN'S EMERGENCY DEPARTMENT}

${ }^{1}$ RA Hastings, ${ }^{2} \mathrm{AJ}$ Lunn, ${ }^{3} \mathrm{~J}$ Surridge. 'Department of Paediatrics, Nottingham Children's Hospital, Nottingham, UK; ${ }^{2}$ Children's Renal and Urology Unit, Nottingham Children's Hospital, Nottingham, UK; ${ }^{3}$ Children's Emergency Department, Derbyshire Children's Hospital, Derby, UK

\subsection{6/archdischild-2015-308599.92}

Aims To examine the follow up of children with microscopic haematuria/proteinuria in the children's emergency department
(CED) and to see if it differs from the perceived practice of CED doctors.

Methods An audit of children with a diagnosis of 'viral URTI' or 'viral illness' during one month in a busy ( $>30,000$ attendances/year) CED was performed. The follow up of those children with a recorded positive urine dipstick was examined.

A survey of responses to scenarios of children with an incidental finding of microscopic haematuria/proteinuria (with no overt signs of renal disease) was used. The survey was sent to SHO grade doctors and registrars and asked for their current practice in arranging follow up of children with positive urine dipstick results.

Results 174 children were audited with 24 of them having a documented positive urine dipstick result. Seventeen children had a single positive (either haematuria/proteinuria), none had follow up. Seven children had at least $2+$ of either proteinuria or haematuria and only one of these had any form of follow up arranged (14\%).

Online survey of SHO doctors (8) and registrars (12) showed that for a child with a $1+$ positive urine dip only 5 doctors (25\%) would arrange follow up. However 17 doctors (85\%) said they routinely offer follow up to children with at least $2+$ on urine dip (either haematuria or proteinuria).

Conclusions Approximately 2/3 of microscopic haematuria/proteinuria in children without specific renal symptoms resolves. Ensuring resolution is important since up to $50 \%$ of children in whom it persists have renal disease. ${ }^{1}$ In our CED, only $14 \%$ of children with at least $2+$ positive urine dipstick had follow up arranged.

On survey, $85 \%$ of doctors working in CED stated that their current practice is to offer follow up to these same children. In regards to the management of haematuria/proteinuria, doctors' 
perceived practice in a busy CED setting differs markedly from their actual practice.

\section{REFERENCE}

1 Geary DF, Schaefer F. Comprehensive Pediatric Nephrology. Philadelphia: Mosby; 2008

\section{G94(P) EMERGENCY DEPARTMENT TEAM WELLBEING. HOW HAPPY ARE WE REALLY?}

${ }^{1} \mathrm{~A}$ Bull, ${ }^{1,2} \mathrm{C}$ Bevan. 'Children's Emergency Department, Royal Alexandra Children's Hospital, Brighton and Sussex University Hospitals NHS Trust, Brighton, UK; ${ }^{2}$ Brighton and Sussex Medical School, Brighton, UK

\subsection{6/archdischild-2015-308599.93}

Aims There is good evidence that high staff moral and satisfaction improve quality of care. The aim of this study was to assess our baseline levels of staff satisfaction within a busy Children's Emergency Department (CED) team, to understand what the department does well and not so well and what and how could we improve.

Method All staff; nursing, medical and administrative, in CED answered a brief 9 question online survey via email. This included both 1-10 rating and free text questions.

Results 80 staff received the questionnaire, 38 (48\%) responded. The mean 'happiness' rating was $6.19 / 10$ with little difference between professions (nurses 6.6, doctors 7.0), staff rated how 'valued' they feel as 6.19. Staff were asked to rate the department in a number of parameters (Figure 1).

The results highlighted lots of positives in the department e.g. tea rounds, social outings, team working and communication. The main areas for improvement suggested were in the relationship and communication between medical and nursing staff. Suggested interventions included: more multidisciplinary meetings, training, and social activities, also listening without interruptions, and valuing all colleagues' opinions.

Conclusion This study has provided a number of ideas for interventions within the department to improve staff wellbeing. The anonymous feedback method allowed true reflections of staff happiness and highlighted areas for future development. Communication was particularly highlighted- e mail is used for a large amount of our interdepartmental communication and on

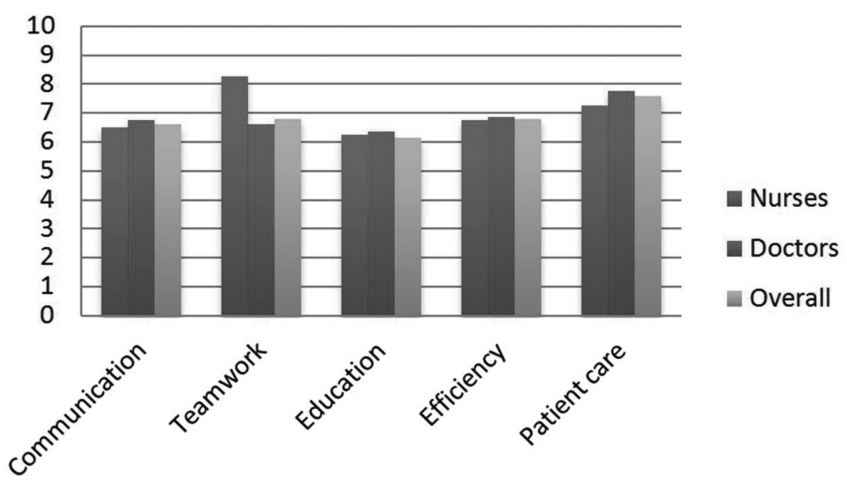

Abstract G94(P) Figure 1 How does our department perform in the following areas?

investigation of our poor response rate it appears that staffs rarely check their hospital e mails address. Our first implementation is to improve this basic form of communication. To also implement a short simple department meeting for prior to handover thus capturing more nursing and medical staff who cannot regularly attend the department meetings. Simple service improvements were also suggested which will be considered to enhance patient care.

\section{G95(P) BEST PRACTICE: ONE OR TWO DOSES OF DEXAMETHASONE FOR THE TREATMENT OF CROUP?}

${ }^{1} \mathrm{~F}$ Roked, ${ }^{2} \mathrm{M}$ Atkinson, 'S Hartshorn. 'Emergency Department, Birmingham Children's Hospital, Birmingham, UK; ${ }^{2}$ General Paediatrics, City and Sandwell Hospital, Birmingham, UK

\subsection{6/archdischild-2015-308599.94}

Aim A systematic review of 43 randomised controlled trials (RCTs) concluded that single dose oral dexamethasone is effective in the treatment of croup. Dexamethasone was associated with an improved Westley score at $6 \mathrm{~h}$ to $12 \mathrm{~h}$ with an effect size of $-1.0(95 \%$ CI -1.5 to -0.6$)$ which was significant, but was no longer significant at $24 \mathrm{~h}$. To date, no RCTs have determined whether administering two doses of dexamethasone, compared with a single dose, improves outcomes in children with

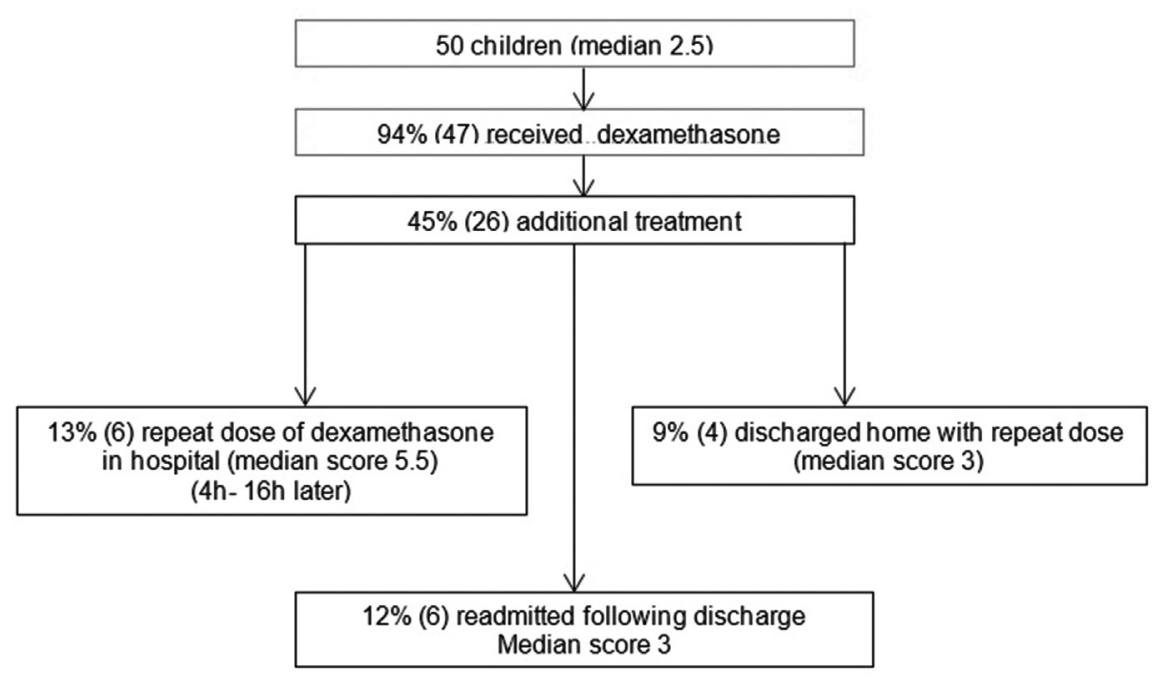

